\title{
EKSPLORASI DESAIN SIRKUIT BALAP MOBIL FORMULA SATU DI MAKASSAR DENGAN PENDEKATAN ARSITEKTUR MODERN
}

\author{
Mutmainnah $^{1 *}$, Wasilah ${ }^{2}$, Akbar Rusli ${ }^{3}$ \\ Arsitektur UIN Alauddin Makassar, Arsitektur UIN Alauddin Makassar, Arsitektur UIN \\ Alauddin Makassar \\ e-mail:*1mutmainnah_sr@yahoo.com,wasilah@uin-alauddin.ac.id,akbar@gmail.com
}

\begin{abstract}
Abstrak_ Indonesia merupakan salah satu negara yang memiliki banyak atlet balap berprestasi dalam taraf internasional. Keberadaan sirkuit balap sangat dibutuhkan para atlet untuk menunjang kegiatan dan mengasah kemampuan balap yang dimiliki. Namun, ketersediaan sirkuit yang sesuai dengan standar internasional di Indonesia masih sangat minim. Oleh karena itu, penelitian ini memberikan ide desain sirkuit balap mobil formula satu di Makassar dengan pendekatan arsitektur modern. Melalui metode eksplorasi desain yaitu metode penjabaran ide dan gagasan yang dirumuskan dalam bentuk gambar. Hasil yang diperoleh berupa tata massa bangunan dipilih sistem terpusat, dimana lintasan yang menjadi pusatnya. Sehingga bangunan disekitarnya berorientasi ke lintasan. Sistem sirkulasi dari dan menuju tapak dibagi menjadi dua dimana sirkulasi untuk pengunjung dipisah dengan sirkulasi untuk team balap. Jalur masuk dan keluar untuk pengunjung juga dipisah, dengan lebar masingmasing jalan $15 \mathrm{~m}$. Sedangkan bentuk bangunan mengambil analogi bentuk dari mobil formula satu dan bentuk aerodinamika dari mobil formula satu. Aerodinamika adalah pergerakan udara ketika berinteraksi dengan benda padat. Dalam hal kendaraan, aerodinamika adalah kecepatan kendaraan dan hambatan udara ketika kendaraan itu melaju. Penerapan tema arsitektur modern pada bangunan dapat dilihat dari bidangbidang kaca yang lebar, jenis material yang digunakan diekspos secara polos, dan dari bahan material yang digunakan.
\end{abstract}

Kata kunci : Aerodinamika, Arsitektur Modern, Eksplorasi Desain, Sirkuit.

\begin{abstract}
Indonesia is one of the countries that have many athletes of racing achievement in international level. The existence of a racing circuit is needed athletes to support activities and hone the ability of racing owned. However, the availability of circuits that comply with international standards in Indonesia is still very minimal. Therefore, this study provides the idea of the design of the formula one race circuit in Makassar with the approach of modern architecture. Through the method of exploration design is the method of elaboration of ideas and ideas formulated in the form of images. The results obtained in the form of building mass order selected centralized system, where the path to be the center. So the surrounding buildings oriented to the track. The circulation system from and to the tread is divided into two where the circulation for the visitor is separated by circulation for the racing team. Entrances and exits for visitors are also separated, each width by road $15 \mathrm{~m}$. While the shape of the building takes the analogy of the form of the formula one car and the form of aerodynamics of the formula one car. Aerodynamics is the movement of air when interacting with solid objects. In terms of vehicles, aerodynamics is the speed of the vehicle and the air resistance when the vehicle is driving. The application of modern architectural themes in buildings can be seen from the wide glass fields, the type of material used is exposed innocently, and of the materials used.
\end{abstract}

Keywords : Aerodynamics, Modern Architecture, Design Exploration, Circuit

\footnotetext{
${ }^{1}$ Arsitektur UIN Alauddin Makassar

${ }^{2}$ Arsitektur UIN Alauddin Makassar

${ }^{3}$ Arsitektur UIN Alauddin Makassar
} 


\section{PENDAHULUAN}

Fasilitas olahraga di bidang otomotif seperti sirkuit balap bertaraf internasional mampu memberikan nilai tambah Indonesia sebagai negara berkembang. Dengan adanya sirkuit balap motor dan mobil mampu mengangkat citra negara dalam skala internasional, ditandai oleh kepercayaan publik internasional untuk menggelar kejuaraan balap bergengsi di dunia seperti MotoGP dan Formula Satu. Hal ini juga berdampak pada sektor ekonomi karena memberikan devisa dari penyelenggaraan lomba tersebut.

Harapan untuk menjadikan Indonesia sebagai tuan rumah untuk menyelenggarakan balap internasional sampai sekelas balap mobil Formula Satu menjadi dasar pemikiran pemilihan tema penelitian ini. Namun sayangnya, sampai saat ini tujuan untuk menyelenggarakan balap mobil Formula Satu di sirkuit yang ada di Indonesia seperti sirkuit Sentul yang berskala internasional belum dapat terlaksana. Dikarenakan Sebagai kejuaraan yang paling tertinggi didalam FIA (Federation Internationale dei' Automobile), penyelenggara balap Formula Satu, fasilitas dan lintasan balap dari sirkuit penyelenggara harus bertaraf internasional dan memiliki lisensi FIA tingkat 1, dengan lisensi itu, sirkuit dapat menyelenggarakan semua kejuaraan berskala internasional dalam aturan FIA, dengan syarat mampu membayar kontrak yang ditawarkan oleh Bernie Ecclestone (CEO Formula 1). Terselenggaranya kejuaraan balap berskala internasional akan memberikan dampak positif secara langsung bagi negara penyelenggara. (Putra, 2008)

Disamping itu, seringkali dijumpai adanya balapan liar dijalan umum, yang dapat membahayakan pengendara itu sendiri, pengguna jalan lainnya serta mengganggu aktifitas warga yang bermukim di area yang sering dijadikan lintasan balapan tersebut. Khususnya daerah Makassar biasanya dijumpai di jalan Veteran, jalan Bandang terjadi balapan liar setiap sabtu malam yang di adakan atas inisiatif individu para penghobi balap. Dengan melihat kondisi yang ada dan disertai dengan beberapa pertimbangan kegiatan-kegiatan yang sangat mengandung resiko tersebut, perlu dicarikan jalan pemecahan, yaitu dengan membuka suatu wadah, sarana, tempat untuk menyalurkan kegiatan tersebut. Salah satu jalan pemecahannya yang di anggap paling sesuai adalah dengan dilakukannya pembangunan sirkuit balap.

Saat ini di Indonesia telah memiliki sirkuit balap internasional yang bernama Sirkuit Sentul, namun kejuaraan internasional sekelas balap mobil Formula Satu belum bisa di selenggarakan di sirkuit sentul. Hal ini dikarenakan Sirkuit Sentul masih berlisensi FIA tingkat 2 dan masih banyak kekurangan yang dimilikinya mulai dari fasilitas, kapasitas dan standar-standar yang diajukan FIA sebagai sirkuit berlisensi tingkat 1

Dalam beberapa tahun belakangan, Indonesia sering mengikut sertakan atlet-atletnya untuk berlaga dalam kejuaraan balap mobil berskala internasional. Atlet-atlet seperti Rio Hariyanto, Ananda Mikola, Moreno Suprapto, Sean Gelael, Emmanuel Amandio, dan Alexandra Asmasoebrata merupakan wakil Indonesia yang berlaga. Para pembalap ini memiliki tujuan untuk berprestasi dan mengharumkan nama bangsa, maka dari itu perlunya sebuah sarana dan fasilitas yang mendukung. Di Indonesia itu sendiri ada beberapa jenis kejuaraan perlombaan balap mobil yang diadakan tiap tahunnya oleh IMI seperti: Indonesia Touring Car Championship (ITCC), Drag Race, Karting, Rally, Off Road, Slalom, Time Rally, dan Drift. 


\begin{tabular}{|c|c|c|c|c|}
\hline \multirow{2}{*}{ No } & \multirow{2}{*}{ Jenis Kegiatan } & \multicolumn{3}{|c|}{ Jumliah Kegianan } \\
\hline & & 2013 & 2014 & 2015 \\
\hline 1 & Rally & i & I & 1 \\
\hline 2 & Spuint Rally & 1 & I & II \\
\hline 3 & Adwenture Om Road & $\mathrm{I}$ & 1 & $=$ \\
\hline 4 & Sprint OT Rond & 3 & 2 & - \\
\hline 5 & Time Rally & 2 & 2 & - \\
\hline 6 & Dras Race & 1 & 2 & $=$ \\
\hline 7 & Slalom Test & I & I & I \\
\hline 8 & Balap Motor & 2 & 3 & 2 \\
\hline 9 & Mobulinoss & 1 & I & 2 \\
\hline 10 & Grasstrack & 3 & 2 & 2 \\
\hline 11 & Drag Bike & i & i & I \\
\hline
\end{tabular}

Dengan melihat data diatas maka dapat disimpulkan bahwa kegiatan otomotif di Sulawesi Selatan khususnya di Makassar berkembang cukup pesat khususnya pada balap motor atau lebih dikenal dengan Road Race merupakan kegiatan yang paling banyak. Data ini pula menunjukkan bagaimana tingginya minat masyarakat dengan kegiatan olahraga otomotif.

Penempatan perencanaan sirkuit ini letaknya sengaja ditempatkan di kawasan pantai losari dengan pertimbangan bahwa pantai losari adalah ikon pariwisata kota Makassar, sehingga di harapkan dengan adanya "sirkuit balap mobil Formula Satu" yang bertaraf internasional dapat dijadikan jenis wisata baru yaitu wisata olahraga mancanegara, yang berdampak meningkatkan pendapatan daerah serta mempromosikan Kota Makassar. Dimana lokasi ini didukung dengan fasilitas seperti hotel berbintang, akses yang mudah dari bandar udara internasional, pelabuhan internasional, tujuan wisata dan pusat perbelanjaan.

Adapun konsep pendekatan yang digunakan adalah pendekatan arsitektur modern. Pendekatan ini menganut faham Form Follows Function (bentuk mengikuti fungsi). Arsitektur modern dianggap sesuai dengan sifat sirkuit balap yaitu memiliki satu gaya Internasional dan tanpa adanya keseragaman yang menjadi suatu kesatuan arsitektur yang dapat menembus budaya dan geografis. Penekanan perancangan difokuskan pada space. Hal ini dianggap sesuai dengan karakteristik sirkuit pada umumnya dan selaras dengan gaya bangunan modern disekitar pantai losari.

Berbagai macam pertimbangan yang telah diuraikan diatas menjadi latar belakang dilakukan penelitian mengenai eksplorasi desain perancangan Sirkuit Balap Mobil Formula Satu di Makassar dengan pendekatan arsitektur modern.

\section{A. Metode Pengumpulan Data}

\section{METODOLOGI}

\section{a. Studi Literatur}

Berupa data dari media massa (internet, koran, buku), yang isinya tentang:

a) Isu perkembangan sirkuit

b) Data-data standar perancangan sirkuit yang memenuhi standar internasional (dalam hal ini organisasi FIA) yang berlaku. 
c) Pendekatan teoritis yaitu mempelajari dasar-dasar teoritis termasuk sejarah dan pengertian sirkuit, perkembangannya di dunia dan faktor yang terpengaruh dengan adanya sirkuit melalui pustaka untuk kelayakan program dengan tema perancangan.

\section{b. Pengamatan Langsung}

Data-data yang didapat berupa:
a) Kondisi lahan
b) Potensi, karakter dan kondisi lahan
c) Studi Preseden

\section{B. Metode Analisis Data}

Metode analisis data yang digunakan adalah metode eksplorasi desain. Metode ini merupakan proses penjabaran ide dan gagasan desain yang akan dirumuskan dalam bentuk gambar. Desain yang dihasilkan berupa gambaran perpaduan antara kondisi eksisting tapak dan landasan teori arsitektur modern yang digunakan, sehingga menghasilkan konsep desain yang sesuai dengan karakteristik lokasi tapak, kebutuhan ruang, transformasi bentuk, dan konsep adaptasi terhadap lingkungan.

\section{HASIL DAN PEMBAHASAN}

Lokasi sirkuit berada pada area strategis yaitu berada di kecamatan Tamalate yang merupakan kawasan pusat kota, kawasan bisnis terpadu, kawasan olahraga terpadu dan kawasan budaya terpadu. Lokasi tapak yang dipilih berada di selat Makassar dengan cara reklamasi terpisah dengan daratan.

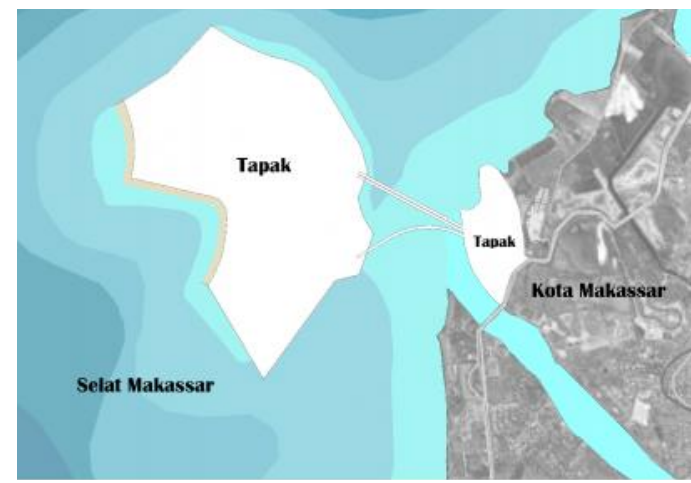

\section{A. Tata Massa}

Gambar 1. Kondisi tapak sebelum dan setelah reklamasi

Konsep desain tapak yaitu terpusat dimana lintasan balap menjadi pusatnya, sehingga bangunan sekitarnya berorientasi ke lintasan. Kenyamanan aktivitas sirkulasi manusia dan kendaraan, dan kesesuaian zoning elemen-elemen tapak, perencana ingin agar aktivitas sirkulasi dalam tapak berjalan lancar, dan penempatan elemen tapak sesuai dengan sifat zoningnya, misalnya penempatan pintu masuk tapak yang sifatnya publik maka perlu diletakkan di area depan yang berhubungan langsung dengan jalan utama sedangkan bangunan penunjang yang sifatnya privat maka diletakkan di area yang lebih khusus. 

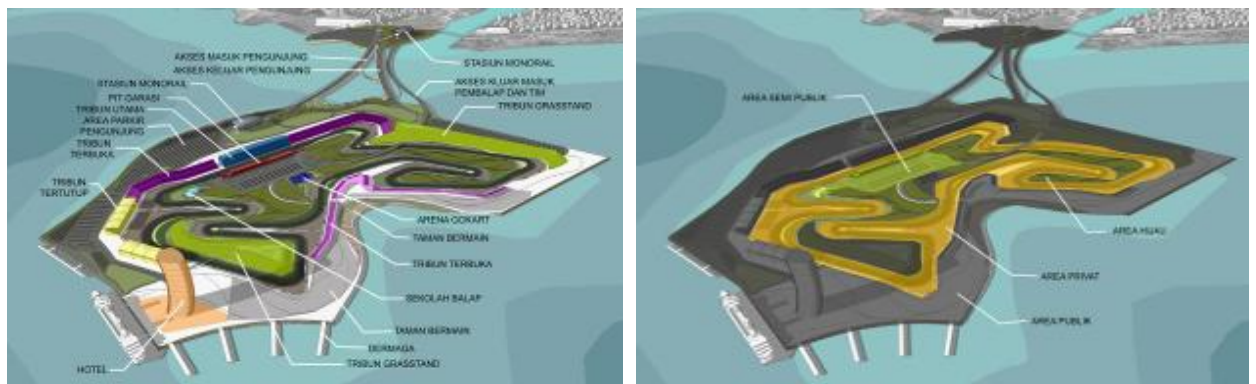

Gambar 2. Konsep Tata Massa dan Zonasi Tapak

\section{B. Konsep Vegetasi dan Orientasi Bangunan Terhadap Lintasan Matahari}

Peningkatan vegetasi sangat dibutuhkan pada tapak untuk menjaga kondisi tanah dan lingkungan tapak.

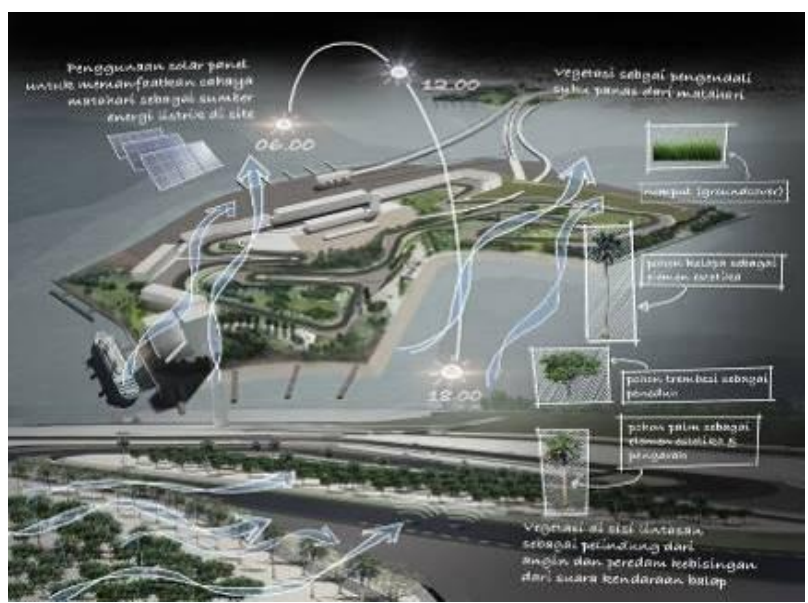

Gambar 3. Konsep Vegetasi dan orientasi bangunan

Sirkulasi dari dan menuju tapak dibagi menjadi dua dimana sirkulasi untuk pengunjung dipisah dengan sirkulasi untuk team balap. Jalur masuk dan keluar untuk pengunjung juga dipisah, dengan lebar masingmasing jalan $15 \mathrm{~m}$.

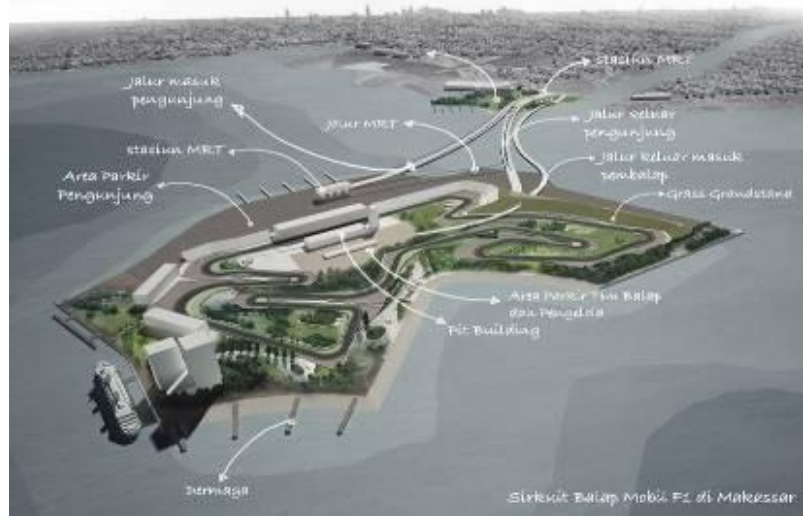

Gambar 4. Konsep sirkulasi

\section{Konsep Bentuk Bangunan}

Bentuk bangunan mengambil analogi bentuk dari mobil formula satu dan bentuk aerodinamika dari mobil formula satu. Aerodinamika adalah pergerakan udara ketika berinteraksi 
Wasilah,

Mutmainnah, Akbar Rusli

dengan benda padat. Dalam hal kendaraan, aerodinamika adalah kecepatan kendaraan dan hambatan udara ketika kendaraan itu melaju.

Penerapan tema arsitektur modern pada bangunan dapat dilihat dari bidang-bidang kaca yang lebar, jenis material yang digunakan diekspos secara polos, dan dari bahan material yang digunakan.

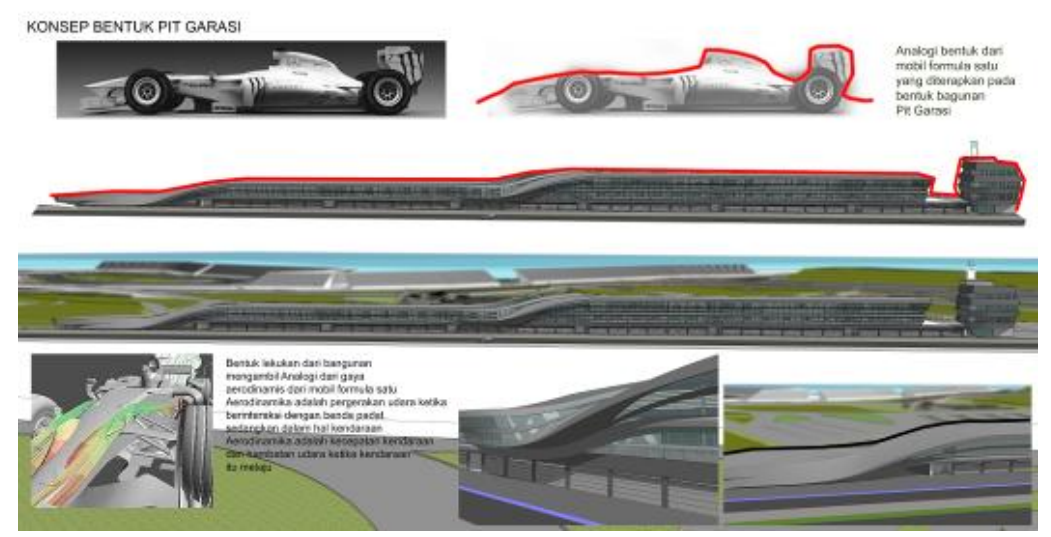

Gambar 5. Konsep Bentuk Bangunan Pit

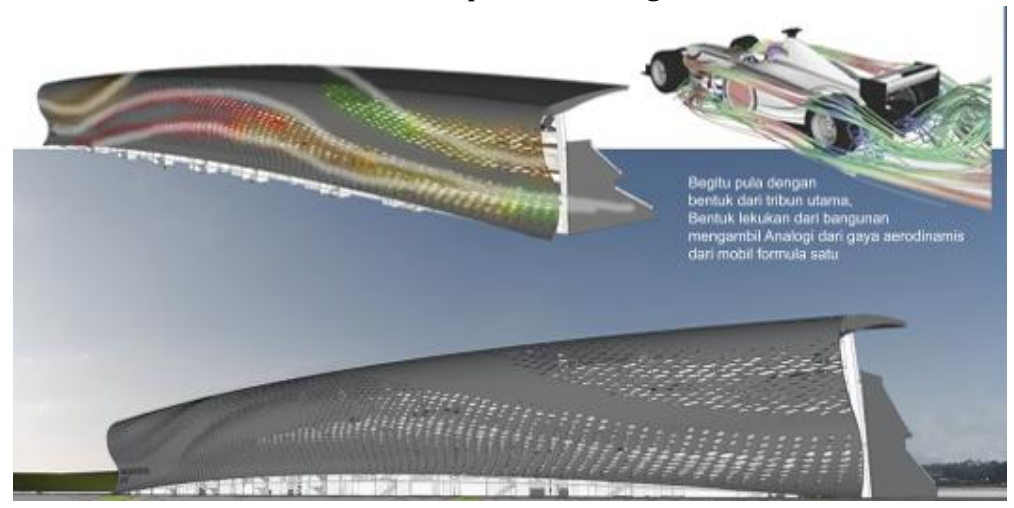

Gambar 6. Konsep Bentuk Tribun Utama

\section{Konsep Material dan Struktur Bangunan}

Material dan Struktur Bangunan

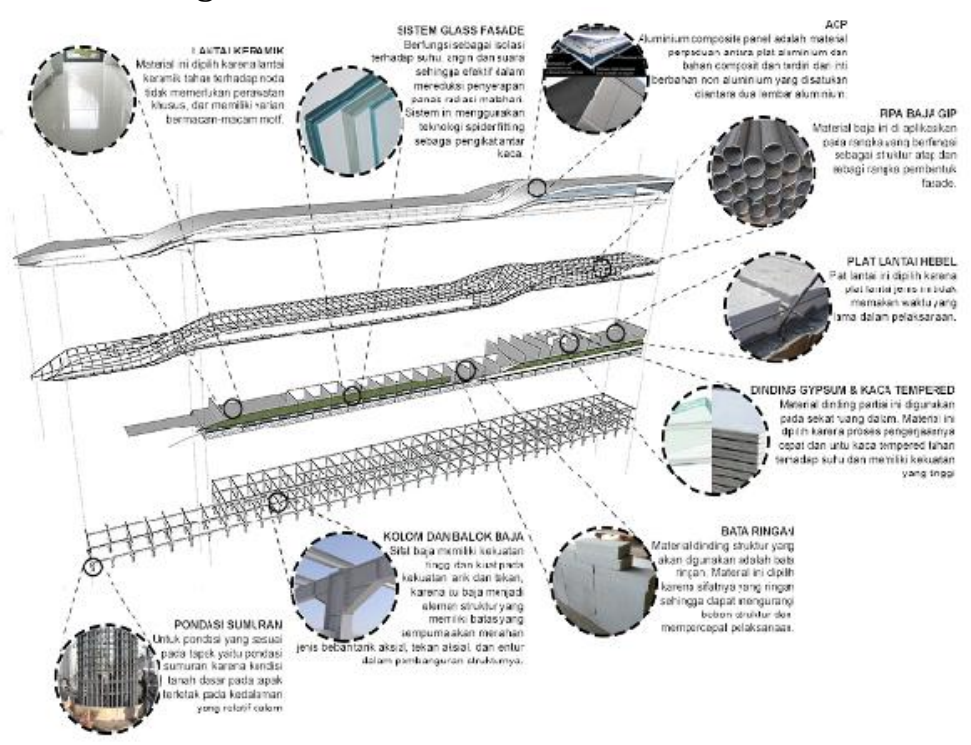

Gambar 7. Konsep material dan struktur bangunan pit 


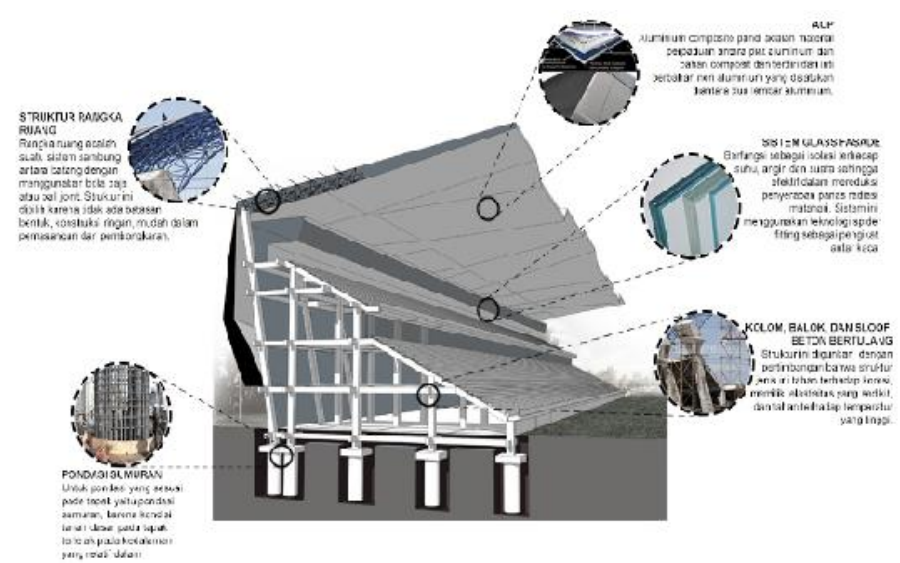

Gambar IV.10. Konsep material dan struktur tribun utama

\section{E. Konsep Utilitas Bangunan}

Konsep utilitas adalah merupakan suatu konsep yang menjelaskan kelengkapan fasilitas bangunan yang digunakan untuk menunjang tercapainya unsur-unsur kenyamanan, kesehatan, keselamatan, kemudahan komunikasi dan mobilitas dalam bangunan. Sistem utilitas yang diaplikasikan pada gedung ini sesuai dengan pembahasan pada bab 3 (Hal.103), meliputi :

1. Sistem jaringan air bersih

2. Sistem jaringan air kotor/buangan

3. Sistem elektrikal

4. Sistem keamanan

5. Sistem komunikasi

6. Sistem tata suara

7. Sistem sampah

\section{KESIMPULAN}

Konsep Desain Sirkuit Balap Mobil Formula Satu di Makassar dengan Pendekatan Arsitektur Modern terdiri dari pengolahan batas tapak, pengolahan kontur tapak, pengolahan vegetasi, pengolahan sirkulasi dalam dan luar tapak, pengolahan orientasi bangunan terhadap matahari, dan pengolahan zoning dalam tapak. Tata massa bangunan yang digunakan yaitu sistem terpusat, dimana lintasan yang menjadi pusatnya. Sehingga bangunan disekitarnya berorientasi ke lintasan. Sistem sirkulasi dari dan menuju tapak dibagi menjadi dua dimana sirkulasi untuk pengunjung dipisah dengan sirkulasi untuk team balap. Jalur masuk dan keluar untuk pengunjung juga dipisah, dengan lebar masingmasing jalan $15 \mathrm{~m}$. Sedangkan Bentuk bangunan mengambil analogi bentuk dari mobil formula satu dan bentuk aerodinamika dari mobil formula satu. Aerodinamika adalah pergerakan udara ketika berinteraksi dengan benda padat. Dalam hal kendaraan, aerodinamika adalah kecepatan kendaraan dan hambatan udara ketika kendaraan itu melaju. Penerapan tema arsitektur modern pada bangunan dapat dilihat dari bidang-bidang kaca yang lebar, jenis material yang digunakan diekspos secara polos, dan dari bahan material yang digunakan. 


\section{DAFTAR REFERENSI}

Heinz Frick, Pujo L Setiawan. 2002. Ilmu Konstruksi Perlengkapan dan Utilitas Bangunan Cara Perlengkapan Gedung Ilmu Konstruksi Bangunan 2. Kanisius : Yogyakarta

Chiara, Joseph De dan John Callender.1983.Times Server Standards for building types .Mc-Graw-Hill Publishing Company: United State

Ching, Francis D.K. 2003. Ilustrasi Konstruksi Bangunan. Penerbit Erlangga, Jakarta

Dipohusodo, Istimawan. 1994, Strukutr Beton Bertulang, Gramedia Pustaka Utama, Jakarta.

Neufert, Ernest. 1997. Data ArsitekJilid 1. Erlangga: Jakarta

Neufert, Ernest. 2002. Data ArsitekJilid II. Erlangga: Jakarta

Tarebbang, Ir. Zainal.1999, Struktur Bentang Lebar 2. Makassar : FT-UH

Tanggoro, Dwi.2010. Utilitas Bangunan. Penerbit Universitas Indonesia : Jakarta Kasim,

Syamsunar. 2006. Sirkuit Balap Otomotif International Di Makassar. Skripsi; Jurusan Arsitektur

Fakultas Teknik Universitas Hasanuddin

FIA. 2013. Yearbook of Automobile Sport 2013. Spanyol: Federasi Internasional Automobile.

PU dan Menpora. 1994. Tata Cara Perencanaan Teknik Bangunan Gedung Olahraga. Yayasan LPMB:

Bandung.

Pengda IMI Sulawesi Selatan. 2015. Peraturan Olahraga Kendaraan Bermotor. Makassar. 